\title{
AMENDMENTS
}

\section{Author Correction: Topological matter: Shrewd detectives find a dissipation channel}

\section{Bernd Gotsmann (1D)}

Correction to: Nature Materials https://doi.org/10.1038/s41563-019-0509-y, published online 14 October 2019.

In the version of this News \& Views originally published, the standfirst incorrectly said the material was $\mathrm{Bi}_{2} \mathrm{Se}_{3}$; it should have been $\mathrm{Bi}_{2} \mathrm{Te}_{3}$. This has now been corrected in the online versions of the News \& Views.

Published online: 29 October 2019

https://doi.org/10.1038/s41563-019-0544-8

๑ Springer Nature Limited 2019

\section{Author Correction: Reciprocal space imaging of ionic correlations in intercalation compounds}

Matthew J. Krogstad (D), Stephan Rosenkranz DD, Justin M. Wozniak, Guy Jennings, Jacob P. C. Ruff, John T. Vaughey (D) and Raymond Osborn (iD)

Correction to: Nature Materials https://doi.org/10.1038/s41563-019-0500-7, published online 21 October 2019.

In the version of this Article originally published, the first line of the acknowledgements was missing 'Office of Basic Energy Sciences' after 'Office of Science'; it should have read 'This work was supported by the US Department of Energy, Office of Science, Office of Basic Energy Sciences, Materials Sciences and Engineering Division and Scientific User Facilities Division' This has now been corrected.

Published online: 30 October 2019

https://doi.org/10.1038/s41563-019-0545-7

(c) The Author(s), under exclusive licence to Springer Nature Limited 2019

\section{Author Correction: Unified picture of anionic redox in $\mathrm{Li} / \mathrm{Na}$-ion batteries}

Mouna Ben Yahia, Jean Vergnet $\mathbb{D}$, Matthieu Saubanère $\mathbb{D}$ and Marie-Liesse Doublet (D)

Correction to: Nature Materials https://doi.org/10.1038/s41563-019-0318-3, published online 18 March 2019.

In the version of this Article originally published, the following sentence was missing from the acknowledgements: 'Part of this work was supported by the EU through the POROUS4APP project-H2020-NMP-PILOT-2015 no. 686163.' This has been corrected in the online versions of the Article.

Published online: 11 November 2019

https://doi.org/10.1038/s41563-019-0547-5

(C) The Author(s), under exclusive licence to Springer Nature Limited 2019 